\title{
Effect of flat slab to progressive collapse on irregular structures building
}

\author{
Roni Suhendra ${ }^{1}$, Zulfikar Djauhari ${ }^{1}$, Reni Suryanita $^{1}$, and Enno Yuniarto ${ }^{1}$ \\ ${ }^{1}$ Civil Engineering Department, University of Riau, Pekanbaru, 28293, Indonesia
}

\begin{abstract}
Technological developments in the field of construction today increasingly developed, structures built not only irregular but also irregular. Story of the irregular-structure building significantly shaped affect the building collapse. The collapse of this building can be a collapse of natural and artificial collapse. The natural collapse was a collapse caused by the load capacity received by building or exceeds the capabilities of the structure itself. The potential of structural failure due to their natural collapse can lead to progressive collapse. This research aimed to analyse the influence of flat slab against progressive collapse at irregular building structures, and determine the type of collapse that occurred at irregular building structures. This research was conducted by analysing the structural elements of the first destroyed by the addition of the maximum load. The analysis is done by eliminating one or more of the critical column based on the General Service Administration (GSA). Examination of the power structures using finite element based software, based on the value Demand Capacity Ratio (DCR). Irregular building structures undergo a progressive collapse if the value of DCR $>1$. The analysis showed a progressive collapse does not occur at irregular building structures, due to the building using structural elements in the form of a flat slab. The collapse happened only on some elements of the building structure, does not occur in the whole structure of the building.
\end{abstract}

\section{Introduction}

The collapse of the World Trade Center (WTC) in New York on September 11, 2001, became phenomenal because of the structure collapse with progressive collapse. The impact of aircraft crashes that triggered fires on some buildings make a local failure of structures in the area of the plane crash. Failure of the structure gives a gradually vertical load to the below floor and make progressive collapse in the building.

Based on the type of collapse occur, progressive collapse divided into pancake-type, zipper-type, domino-type, section-type, instability-type and mixedtype collapse (Starossek, 2009). The WTC building collapse with pancake-type that makes small opportunity to save because the collapse occurs very quickly. In contrast to the type of domino that occurs gradually, it can provide more significant opportunities to save people.

Potential structural failures due to the load capacity received by buildings or buildings exceeding the capacity of the structure itself can result in progressive collapse. Progressive collapse is a collapse caused by a collapse of one or more structural elements which causes a collapse of the progressive elements next to it, resulting in the structure experiencing the partial or complete collapse of the structure. Structural elements in the form of beams, columns, floor slabs, and walls are very influential on a progressive collapse that occurs in building structures, for example, floor plate structural elements used by conventional and flat slab types significantly affect building collapse when the progressive collapse occurs in one column element or the building beam itself is eliminated.

The purpose of this study is to analyse the effect of flat slabs on the ground floor for progressive collapse. The benefits of this study are as follows.

a. Provide information for building planning to predict the progressive collapse characteristics of regular and irregular building structural components.

b. Provide information on the type of building collapse in case of demolition of the regular and irregular building structure.

\section{Regular and Irregular Building Structure}

Based on SNI 1726-2012 on Earthquake Resilience Planning Procedures for Building and Non-Building Structures, building structures are classified as regular and irregular buildings. The classification is based on the horizontal and vertical configuration of the building structure. Specifically, in this study, only limits the problem of structural irregularities in the horizontal direction as in Table 1.

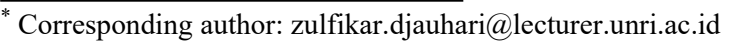


Table 1. Horizontal Irregularities in Building Structure

\begin{tabular}{cl}
\hline No & Type And Explanation Of Irregularity \\
\hline 1a & Torque irregularities are defined to exist if the maximum \\
level inter-floor drift, the calculated torque including the \\
unexpected, at a transverse end of the structure against the axis \\
of more than 1.2 times the mean inter-floor deviation at both \\
ends of the structure. \\
\hline 1b \\
Excessive torque irregularities are defined to exist if the \\
maximum level inter-floor drift, the calculated torque \\
including the unexpected, at a transverse end of the structure \\
against the axis of more than 1.4 times the mean inter-floor \\
deviation at both ends of the structure. \\
\hline $\mathbf{2}$ The inner angular irregularity is defined if both the \\
projected structural planes of the inner corners are greater than \\
15\%t of the dimensions of the structural-plan in a given \\
direction. \\
\hline 3 The irregularities of diaphragmatic discontinuities are \\
defined to exist when there is a diaphragm with discontinuity \\
or sudden variation in stiffness, including those having cut or \\
open areas more significant than $50 \%$ of the gross diaphragm \\
area surrounding it, or an effective diaphragm stiffening \\
change of more than 50 \% from one level to the next.
\end{tabular}
Source: SNI 1726-2012

\section{Progressive Collapse}

The General Services Administration (GSA) provides guidelines for progressive collapse. This guideline aims to reduce the potential for progressive collapse in government offices, assess the potential for progressive collapse of existing government office buildings, and assist in the development process of upgrading facilities. The scenario in this guide is to delete the columns on the first floor. Recommended locations in column deletion are as follows.

1. Removal the column in the middle or near the middle of the short side of the structure

2. Removal the column in the middle or near the centre of the long side of the structure

3. Removal the corner column

4. Removal interior columns

In linear or nonlinear static analysis procedures use 2 (DL $+0.25 \mathrm{LL})$ load combination whereas in linear or nonlinear dynamic analysis procedures using $(\mathrm{DL}+0.25 \mathrm{LL})$ load combination with $\mathrm{DL}$ is the dead load and LL is the live load.

The approach is based on Demand Capacity Ratio (DCR) for structural elements and compares DCR values with threshold values to identify structural collapse. DCR is calculated according to the following formula.

$$
\text { DCR }=\text { Qud / Qce }
$$

Qud is the force obtained in the component (moment, axial force, shear and conjugation of force) obtained from the linear elastic analysis, whereas Qce is the relative strength of the component (moment, axial force, shear and conjunction of force combined).
The DCR values allowed for structural elements are as follows.

1) DCR $<2.0$ for regular structural configuration.

2) DCR $<1.5$ for irregular structural configuration.

\section{Modelling and Analysis}

\subsection{Design Standard}

Design based on SNI 03-2847-2013 Structural Concrete Requirements for Building Structure and SNI 1726-2012 earthquake resistance planning procedures for building and non-building structures. The load is given based on SNI 1727-2013 concerning the minimum load for the design of buildings and other buildings.

\subsection{System and Geometry Structure}

The structure of the building reviewed in this study consists of an irregular structure. The building structure used is an irregular 4-storey building structure that has a height of 3 meters for the ground floor and 5 meters for the next floor, so the height of the building is 26.3 meters and functions as a shopping centre.

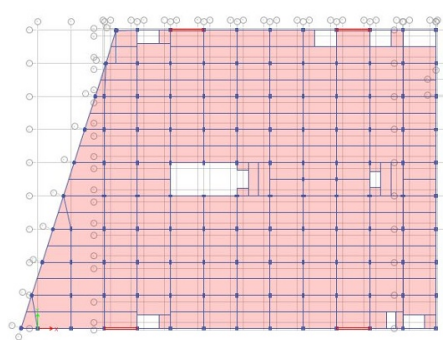

(a)

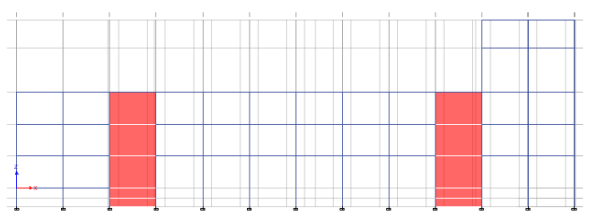

(b)

Fig. 1. The structure of the irregular building: (a) building floor plan and (b) building section.

\subsection{Analysis of Progressive Collapse}

\subsubsection{Analysis of Styles in Time Whole Element.}

Finite element based software is used to obtain internal forces acting on each building's structural elements. The internal forces obtained in the analysis can be axial, shear forces, and moment forces. These styles can be used to analyse the strength of the structure due to the removal of several parts of the column. The calculation of the inner forces is carried out on various combinations of loading based on GSA 2003 criteria 
and SNI 2847-2013. The loading combination used is the maximum loading combination. The maximum loading combination is in combination IV, that is $(1.2$ $\mathrm{DL}+\mathrm{LL}+\mathrm{Ex}-0.3 \mathrm{Ey})$.

\subsubsection{Comparison of Bending Moments}

This comparison of bending moment is made by comparing the ultimate moment to the existing structure and the removed structure, either the removal of the corner of the building column or the removal of the internal column of the building. Due to the removal of several components of the structure, both columns and beams experience varying increases in bending moments.

\subsubsection{Bending Moment Ratio As a Result Maximum Loading}

The results of running using software based on finite elements, the maximum combination of combinations are found in combination 4 (1.2 DL + LL + Ex - 0.3 Ey). Therefore, the ratio of moment bending ratio or calculation of bending moment ratio is done due to structural elements influenced by a combination of loading 4. Comparison of bending moments is calculated based on the comparison of moments on the beam elements and intact columns with beam or column elements that have been erased, either deletion the column corner section and the removal of the internal parts of the building. Increasing the value of the Bending Moment Ratio (BMR) between the beam elements and whole columns with incomplete beam and column elements, in which the incomplete elements are removed from the corner column and deleting the centre column of the building.

The increase in the Bending Moment Ratio (BMR) value between intact beam elements and beam elements can be analysed at the time of column removal at the corner of the building. The highest increase in the value of Bending Moment Ratio (BMR) occurs in beam elements on the first floor of a building with an increased ratio of 1.163 .

Increasing the value of the Bending Moment Ratio (BMR) between intact beam elements and beam elements when removing columns on the inner side of the building, the highest increase in the Bending Moment Ratio (BMR) value occurs in beam elements whose positions are located near the eliminated critical column. The increase in the beam element is 1.798 .

Bending Moment Ratio Analysis (BMR) between whole column elements and column elements at the time of column removal on the corner of the building. The highest increase in the value of Bending Moment Ratio (BMR) occurs in column elements that are located beside the critical column that is omitted, with an increased ratio of 1,228 .

Analysis of increasing Bending Moment Ratio (BMR) value between intact column elements and column elements at column removal on the inner side of the building. The highest increase in the value of the Bending Moment Ratio (BMR) occurs in column elements whose position is next to the critical column that is abolished, with an increased ratio of 1,100 .

\subsubsection{Demand Capacity Ratio (DCR)}

Checking the strength of the structure or determining a structural element experiencing progressive collapse is done using finite element based software based on the calculation of the capacity ratio value or Demand Capacity Ratio (DCR). Demand Capacity Ratio (DCR) is a comparison between the force, load or ultimate moment in the cross-section that occurs $(\mathrm{Pu}$ or $\mathrm{Mu})$ against the moment or nominal load ( $\mathrm{Pn}$ or $\mathrm{Mn})$. The DCR value is a numerical indication related to the strength of each element of the building structure analysed. The irregular building structure experiences progressive collapse if the value of the Demand Capacity Ratio (DCR) is greater than 1, so for regular building structures that experience progressive collapse if the value of the Demand Capacity Ratio (DCR) is greater equal to 2 .

The results of the analysis obtained when deleting critical columns on the angles and inner sides of the building, the building did not experience a complete collapse in the building, but some structural elements were categorised as having collapsed, both in column elements and beam elements in the structure of the building. The building did not experience a complete collapse, due to the influence of the flat slab located on the ground floor of the building that can withstand the maximum loads that occur in some structural elements. As a result of holding back the loads that occur, so that the flat slab on the ground floor of the building suffered a total collapse, but the collapse of the ground floor flat slab did not affect the collapse on the floor above.

\section{Conclusion}

Based on the results of the analysis, it can be concluded that:

1. The irregular building structure did not collapse after the removal of the column.

2. Collapse only occurs in several structural elements, both beam structural elements and column structural elements.

3. The effect of the flat slab on progressive collapse is very influential because the existence of the flat slab after removal of the building column does not experience overall collapse, but some structural elements have collapsed.

4. Flat slab on the ground floor of a building when the critical column and inner sides of a building are removed is collapsed but does not affect the floor above, because the load on the upper floor moves to a flat slab system on the ground floor of the building.

5. The beam and column structural elements that have collapsed during the removal of columns on the side of the corner and the inner side of the building are the structural elements that are 
located around the critical column that is removed.

6. The results of column analysis on the structure of the building show that the column is still able to carry the load when removing columns on the building side of the building and removal of columns on the inner side of the building due to the effect of flat slabs.

\section{Reference}

1.BSN. SNI 1726-2002: Earthquake Resistance Planning Standards for Building. Bandung: Departemen Permukiman dan Prasarana Wilayah. (2002)

2.BSN. SNI 1726-2012: Tata Cara Perencanaan Ketahanan Gempa untuk Struktur Bangunan Gedung dan Non Gedung. Jakarta: Badan Standardisasi Nasional. (2012).

3.BSN. SNI 1727-2013: Beban Minimum untuk
Perancangan Bangunan Gedung dan Struktur Lain. (2013).

4.BSN. SNI 2847-2013: Persyaratan Beton Struktural untuk Bangunan Gedung. Jakarta: Badan Standardisasi Nasional. (2013).

5. General Services Administrator (GSA). Progressive Collapse Analysis and Design Guidelines. (2003)

6. Puskim. Zonasi Gempa Wilayah., (2017)

7. Rakshith, K., \& Radhakrishna. Progressive Collapse Analysis of Reinforced Concrete Framed Structure, (2013)

8. Sunamy, S. L., Binu, P., \& Girija, K. Progressive Collapse Analysis of a Reinforced Concrete Frame Building, (2014)

9. Starossek, U. Progressive Collapse of Structures. (2009).

10. Wang, C., \& Salmon, C. G. Reinforced Concrete Design. Madison, (1989) 